\title{
Is increasing microbiota diversity a novel anti-inflammatory action of marine n-3 fatty acids?
}

\author{
Philip C. Calder ${ }^{1,2}$
}

5

${ }^{1}$ Human Development and Health, Faculty of Medicine, University of Southampton, Southampton, United Kingdom;

${ }^{2}$ National Institute of Health Research Southampton Biomedical Research Centre, University Hospital Southampton National Health Service Foundation Trust and University 10 of Southampton, Southampton, United Kingdom

Address for correspondence: Dr P.C. Calder, Human Development and Health, Faculty of Medicine, University of Southampton, IDS Building, Mailpoint 887 Southampton General Hospital, Tremona Road, Southampton SO16 6YD, United Kingdom

15 Tel: +442381205250

Email:pcc@soton.ac.uk

Running title: Marine n-3 fatty acids and microbiota diversity

20 Funding: The author has received no funding related to this manuscript.

Keywords: Omega-3; Eicosapentaenoic acid: Prostaglandin $\mathrm{E}_{2}$; Colon; Inflammation

Abbreviations: DHA, docosahexaenoic acid; EPA, eicosapentaenoic acid; PG, prostaglandin. 
In the current issue of Journal of Nutrition, Djuric et al. describe a relationship between increased diversity of the gut microbiota and the anti-inflammatory effect of supplemental n3 fatty acids, assessed as colonic prostaglandin (PG) $\mathrm{E}_{2}$ concentrations [1]. The findings, which must be regarded as preliminary and requiring confirmation, suggest a new mechanism by which the marine n-3 fatty acids eicosapentaenoic acid (EPA) and docosahexaenoic acid (DHA) dampen intestinal inflammation. Importantly, rather than sampling fecal microbiota, Djuric et al. [1] sample the microbiome of colonic mucosal biopsies and of stool brushings from an adjacent site within the colon lumen some distance away from the anus. The bacteria present in the colonic mucosa and nearby stool are known to differ [2,3].

There are a number of well described, perhaps interacting, mechanisms by which EPA and DHA exert anti-inflammatory actions $[4,5]$. The oldest described mechanism is the partial replacement of arachidonic acid in the membranes of cells involved in inflammatory responses resulting in decreased availability of substrate for production of pro-inflammatory eicosanoids like $\mathrm{PGE}_{2}$ and leukotriene $\mathrm{B}_{4}$ (see [4,5]). The other main mechanism involves EPA and DHA interfering in the activation of the pro-inflammatory transcription factor nuclear factor kappa-light-chain-enhancer of activated B cells (aka NF- $\kappa \mathrm{B}$ ) resulting in decreased expression of genes encoding pro-inflammatory cytokines, adhesion molecules and enzymes (see $[4,5])$. This mechanism seems to result from several different actions of EPA and DHA including modulation of the formation of pro-inflammatory lipid rafts in response to inflammatory stimuli, activation of peroxisome proliferator activated receptor $\gamma$, and signalling through cell surface G-protein coupled receptor 120 (see [4,5]). The resulting reduction in inflammation is considered to be central to the role of marine n-3 fatty acids in preventing atherosclerosis [6] and in reducing pain and other symptoms in patients with rheumatoid arthritis [7,8]. There is inconsistent evidence of benefit of EPA and DHA in inflammatory bowel diseases [9] and in asthma and other allergic diseases [10]. More recently, the role of EPA and DHA as substrates for the generation of lipid mediators that actively resolve inflammation has been well described, mainly in pre-clinical studies in model systems [11], indicating that these fatty acids possess both anti-inflammatory and proresolving activities. Irrespective of the mechanism of action involved, the increased presence of EPA and DHA in the bloodstream and in the membranes of the cells involved is essential for the described effects to occur. Human studies have reported the linear dose-response relationship between increased intake of EPA and DHA, usually from supplements, and the increased appearance of these fatty acids in blood lipids [12-15] and in circulating 
mononuclear cells $[14,15]$ and neutrophils [16]. The enrichment of cell membranes with marine n-3 fatty acids is accompanied by a decline in content of arachidonic acid and this decline appears to be strongly inversely related to the intake of $n-3$ fatty acids $[14,16,17]$. These relationships are of biological significance. For example, Rees et al. [14] reported: "a significant positive relation between $\mathrm{PGE}_{2}$ production by lipopolysaccharide-stimulated mononuclear cells and mononuclear cell phospholipid arachidonic acid content and a significant negative relation between $\mathrm{PGE}_{2}$ production by lipopolysaccharide-stimulated mononuclear cells and mononuclear cell phospholipid EPA content", "a significant positive relation between $\mathrm{PGE}_{2}$ production and the ratio of arachidonic acid to EPA in mononuclear cell phospholipids" and "a significant negative relation between the change in $\mathrm{PGE}_{2}$ production and the change in mononuclear cell phospholipid EPA content". These relations indicate a close link between the presence of both arachidonic acid and EPA in cell membrane phospholipids and the ability of those cells to produce inflammatory mediators and furthermore that one strategy to regulate inflammation is to modulate the amounts of arachidonic acid and EPA in cell membrane phospholipids. Djuric et al. [1,18] set out to decrease colonic mucosal $\mathrm{PGE}_{2}$ production by $50 \%$, since a reduction of this extent was demonstrated to significantly affect colonic neoplasia in animal models (see [18]). Masoodi et al. [19] reported 63\% lower $\mathrm{PGE}_{2}$ in uninflamed compared with inflamed colonic mucosa from patients with Crohn's Disease. Djuric et al. used serum fatty acids to report on arachidonic acid and EPA levels combined with a personalized dosing approach with an EPA-rich supplement [18]. The basis for this was both animal and human data relating the ratio of EPA to arachidonic acid in serum to colonic $\mathrm{PGE}_{2}$ concentration (see [18]). They identified that a serum EPA to arachidonic acid ratio of about 1 was associated with a $50 \%$ reduction in colonic $\mathrm{PGE}_{2}$ concentration, and that achieving a serum ratio of 1 required an individual dosing regimen of between 2.8 and $8.8 \mathrm{~g}$ EPA+DHA/day (mean $5.5 \mathrm{~g} /$ day) using a supplement with an EPA to DHA ratio of about 3. These data may be compared with those of Rees et al. [14] using $4.95 \mathrm{~g}$ EPA+DHA/day with an EPA to DHA ratio of 4.5 in the supplement. After $12 \mathrm{wk}$, this resulted in a mean plasma phospholipid EPA to arachidonic acid ratio of 0.78 in young men (mean age $24 \mathrm{y}$ ) and of 1.22 in older men (mean age $60 \mathrm{y}$ ) and a mean reduction of lipopolysaccharide-induced $\mathrm{PGE}_{2}$ production from mononuclear cells of $47 \%$ for younger men and 50\% for older men. Curiously, Djuric et al. have not reported colonic mucosa fatty acids in detail in either of their publications $[1,18]$; it would be very informative to know the relationships of the different fatty acids and fatty acid ratios between serum and colonic mucosa. Others have reported higher arachidonic acid, lower 
EPA and a higher ratio of arachidonic acid to EPA in inflamed compared with non-inflamed colonic mucosa from patients with Crohn's Disease [20].

In their earlier paper, Djuric et al. reported a mean $45 \%$ reduction in colonic mucosa $\mathrm{PGE}_{2}$ concentration after 12 wk supplementation with the personalized dose of n-3 fatty acids [18]. In this new paper [1], they report data from the 47 healthy men and women who underwent a colonic mucosal biopsy and luminal stool brushing at study entry and exit, after 12 wk of personalized n-3 fatty acid supplementation. Subjects were aged 25 to $75 \mathrm{y}$ and had a body mass index of between 18 and $40 \mathrm{~kg} / \mathrm{m}^{2}$. The samples were collected 20 to $25 \mathrm{~cm}$ from the anal sphincter. Bacterial diversity was assessed using 16S rRNA sequencing. N-3 fatty acids had little effect on intestinal bacteria with no changes in relative abundance of major phyla or families or in diversity indices. This is generally consistent with the recent findings of Watson et al. [21] with marine n-3 fatty acids in healthy subjects: they reported no significant changes in $\alpha$ or $\beta$ diversity or phyla composition with n-3 fatty acid supplementation. However, Watson et al. [21] did find an increased abundance of several genera, including bifidobacteria, roseburia and lactobacilli with n-3 fatty acid intervention, although these changes did not correlate with erythrocyte n-3 fatty acid incorporation. Djuric et al. [1] found that $\mathrm{n}-3$ fatty acids increased the dis-similarity index between the microbiome in colonic mucosa and luminal brushings. A small group of subjects with high Prevotella abundance at study entry were resistant to the anti-inflammatory effects of n-3 fatty acids. In regression analyses, increases in bacterial diversity in luminal brushings, but not in colonic mucosa, were predictors of lower colonic $\mathrm{PGE}_{2}$ concentrations. Changes in luminal brushing bacterial diversity contributed to 6 to $8 \%$ of the inter-individual variation in the change in colonic $\mathrm{PGE}_{2}$ concentration. The suggestion is that $\mathrm{n}-3$ fatty acids increase diversity in stool microbiota and that this affects colonic mucosal inflammation, as evidenced by lower $\mathrm{PGE}_{2}$ concentrations. An increased colonic mucosa ratio of EPA to arachidonic acid was also associated with decreased colonic mucosa $\mathrm{PGE}_{2}$ concentration, as would be expected, but this did not influence the association of stool bacterial diversity with colonic $\mathrm{PGE}_{2}$ concentrations suggesting that the effect of the bacterial diversity is independent of the colonic mucosa fatty acid changes.

Where does this new research leave us? The personalization of n-3 fatty acid dosing against a physiological outcome is an intriguing, yet effective, approach. Marine n-3 fatty acids might affect diversity of stool microbiota to create a less inflammatory environment for the colonic mucosa. Yet effects of n-3 fatty acids on the microbiota are small. Fat digestion and absorption are efficient, at least in most healthy human subjects, and it is unlikely that 
much EPA and DHA pass through to the lower colon to act as a prebiotic or metabolic substrate. Perhaps a change in systemic inflammation resulting from increased presence of EPA and decreased presence of arachidonic acid is influencing the luminal microbiome. The study by Djuric et al. [1] is important because it highlights a possible new mechanism of action of marine n-3 fatty acids that could be important in promoting health and treating disease. However, the number of subjects investigated is fairly small, the biological effects are small despite the high intakes of EPA used, there is no control of the diet of the participants, and there is no control group with which to compare the temporal changes that are observed in the stool brushing microbiome.

\section{References}

1. Djuric Z, Bassis CM, Plegue MA, Sen A, Turgeon DK, Herman K, Young VB, Brenner DE, Ruffin MT. Increases in colonic bacterial diversity after omega-3 fatty acid supplementation predict decreased colonic prostaglandin $\mathrm{E}_{2}$ concentrations in healthy volunteers. J Nutr 20919; in press.

2. Ringel Y, Maharshak N, Ringel-Kulka T, Wolber EA, Sartor RB, Carroll IM. High throughput sequencing reveals distinct microbial populations within the mucosal and luminal niches in healthy individuals. Gut Microbes 2015;6:173-181.

3. Yasuda K, Oh K, Ren B, Tickle TL, Franzosa EA, Wachtman LM, Miller AD, Westmoreland SV, Mansfield KG, Vallender EJ, et al. Biogeography of the intestinal mucosal and luminal microbiome in the Rhesus macaque. Cell Host Microbe 2015;17:385-391.

4. Calder PC. Marine omega-3 fatty acids and inflammatory processes: Effects, mechanisms and clinical relevance. Biochim Biophys Acta 2015;1851:469-484.

5. Calder PC. Omega-3 fatty acids and inflammatory processes: from molecules to man. Biochem Soc Trans 2017;45:1105-1115.

6. Calder PC, Yaqoob P. Omega-3 (n-3) fatty acids, cardiovascular disease and stability of atherosclerotic plaques. Cell Mol Biol 2010;56:28-37.

7. Abdulrazaq M, Innes JK, Calder PC. Effect of w-3 polyunsaturated fatty acids on arthritic pain: a systematic review. Nutrition 2017;39-40:57-66.

8. Senftleber NK, Nielsen SM, Andersen JR, Bliddal H, Tarp S, Lauritzen L, Furst DE, Suarez-Almazor ME, Lyddiatt A, Christensen R. Marine oil supplements for arthritis pain: A systematic review and meta-analysis of randomized trials. Nutrients 2017;6:42. 
9. Calder PC. Fatty acids and immune function: relevance to inflammatory bowel diseases. Int Rev Immunol 2009;28:506-534.

10. Miles EA, Calder PC. Can early omega-3 fatty acid exposure reduce risk of childhood allergic disease? Nutrients 2017;9:784.

11. Serhan CN. Discovery of specialized pro-resolving mediators marks the dawn of resolution physiology and pharmacology. Mol Aspects Med 2017;58:1-11.

12. von Schacky C, Fischer S, Weber PC. Long term effects of dietary marine $\omega^{-3}$ fatty acids upon plasma and cellular lipids, platelet function, and eicosanoid formation in humans. J Clin Invest 1985;76:1626-1631.

13. Katan MB, Deslypere JP, van Birgelen APJM, Penders M, Zegwaard M. Kinetics of the incorporation of dietary fatty acids into serum cholesteryl esters, erythrocyte membranes and adipose tissue: an 18 month controlled study. J Lipid Res 1997;38:2012-2022.

14. Rees D, Miles EA, Banerjee T, Wells SJ, Roynette CE, Wahle KWJW, Calder PC. Doserelated effects of eicosapentaenoic acid on innate immune function in healthy humans: a comparison of young and older men. Am J Clin Nutr 2006;83:331-342.

15. Browning LM, Walker CG, Mander AP, West AL, Madden J, Gambell JM, Young S, Wang L, Jebb SA, Calder PC. Incorporation of eicosapentaenoic and docosahexaenoic acids into lipid pools when given as supplements providing doses equivalent to typical intakes of oily fish. Am J Clin Nutr 2012;96:748-758.

16. Healy DA, Wallace FA, Miles EA, Calder PC, Newsholme P. The effect of low to moderate amounts of dietary fish oil on neutrophil lipid composition and function. Lipids 2000;35:763-768.

17. Walker CG, West AL, Browning LM, Madden J, Gambell JM, Jebb SA, Calder PC. The pattern of fatty acids displaced by EPA and DHA following 12 Months supplementation varies between blood cell and plasma fractions. Nutrients 2015;7: 6281-6293.

18. Djuric Z, Turgeon DK, Sen A, Ren J, Herman K, Ramaswamy D, Zhao L, Ruffin MT 4th, Normolle DP, Smith WL, Brenner DE. The anti-inflammatory effect of personalized omega-3 fatty acid dosing for reducing prostaglandin E2 in the colonic mucosa is attenuated in obesity. Cancer Prev Res (Phila) 2017;10:729-737.

19. Masoodi M, Pearl DS, Eiden M, Shute JK, Brown JF, Calder PC, Trebble TM. Altered colonic mucosal polyunsaturated fatty acid (PUFA) derived lipid mediators in ulcerative colitis: new insight into relationship with disease activity and pathophysiology.

PLoSOne 2013;8:e76532. 
20. Pearl DS, Masoodi M, Eiden M, Brümmer J, Gullick D, McKeever TM, Whittaker MA, Nitch-Smith H, Brown JF, et al. Altered colonic mucosal availability of n-3 and n-6 polyunsaturated fatty acids in ulcerative colitis and the relationship to disease activity. $\mathrm{J}$ Crohn's Colitis 2014;8:70-79.

21. Watson H, Mitra S, Croden FC, Taylor M, Wood HM, Perry SL, Spencer JA, Quirke P, Toogood GJ, Lawton CL, et al. A randomised trial of the effect of omega-3 polyunsaturated fatty acid supplements on the human intestinal microbiota. Gut 2018;67:1974-1983. 